\title{
PLASMODIUM RELICTUM AS A CAUSE OF AVIAN MALARIA IN WILD-CAUGHT MAGELLANIC PENGUINS (SPHENISCUS MAGELLANICUS)
}

\author{
Andrew S. Fix, ${ }^{1}$ Cheryl Waterhouse, ${ }^{2}$ Ellis C. Greiner, ${ }^{3}$ and Michael K. Stoskopf ${ }^{4}$ \\ 1 Department of Veterinary Pathology, College of Veterinary Medicine, lowa State University, \\ Ames, lowa 50011, USA \\ 2 Blank Park Zoo, Des Moines, lowa 50315, USA \\ ${ }^{3}$ Department of Infectious Diseases, College of Veterinary Medicine, University of Florida, \\ Gainesville, Florida 32610, USA \\ ${ }^{4}$ Division of Comparative Medicine, Johns Hopkins School of Medicine and Department of Medicine, \\ Baltimore, Maryland 21205, USA
}

ABSTRACT: Avian malaria (Plasmodium relictum) caused significant mortality in wild-caught Magellanic penguins (Spheniscus magellanicus) in 1986 at the Blank Park Zoo in Des Moines, Iowa (USA). In early winter, wild birds were captured off the southern coast of Chile and flown to Detroit, Michigan for a 38 day quarantine. After quarantine, 18 birds were dispersed to Lansing, Michigan, six to a facility in Maine, and 46 to Des Moines, Iowa. Upon arrival in Des Moines, several penguins became weak and inactive, had to be force-fed, and died after 2 days. Gross lesions at postmortem included splenomegaly, hepatomegaly, and pulmonary edema. Histopathological examination revealed numerous intraendothelial schizonts in spleen, lung, liver, heart and kidney. Schizonts were generally 16 to $28 \mu \mathrm{m}$ by 11 to $16 \mu \mathrm{m}$ and contained merozoites of two distinct sizes (macromerozoites, nuclei $1.0 \mu \mathrm{m}$; micromerozoites, nuclei $0.5 \mu \mathrm{m}$ ). Based on the morphology of the abundant exoerythrocytic forms, a tentative diagnosis of avian malaria (Plasmodium sp.) was made. Subsequent transmission electron microscopic examination of schizonts in formalized tissue revealed merozoites with tear-shaped rhoptries. Antimalarial therapy was initiated early but deaths continued for 5 mo. Mortality, which eventually totaled $83 \%$, occurred in three distinct waves, each separated by a hiatus of approximately 1 mo. Despite examinations of repeated blood smears, intraerythrocytic Plasmodium relictum was not detected until late in the outbreak. Diagnosis was based on morphologic characteristics including schizonts with eight to 12 merozoites/segmenter and round gametocytes that displaced and turned the infected erythrocyte nucleus. In addition to malaria, penguins showed evidence of aspergillosis, bacterial enteritis (Escherichia coli; Proteus sp.; and Edwardsiella sp.), and helminthiasis (Contracaecum sp. and Tetrabothrius sp.). Based on gross and histological lesions, disease prevalence in this group of penguins was malaria $58 \%$, aspergillosis $61 \%$, enteritis $60 \%$, helminthiasis $26 \%$. Epidemiologic investigation including group transport history, disease prevalence in co-quarantined birds not sent to Des Moines and climatological data implicated Des Moines as the likely site for initial exposure, although information is not conclusive. Stress and concurrent disease certainly contributed to the severe mortality in this group of penguins infected with $P$. relictum.

Key words: Magellanic penguin, Spheniscus magellanicus, avian malaria, Plasmodium relictum, outbreak, pathology, epidemiology, therapy.

\section{INTRODUCTION}

Avian malaria in captive penguins is a well-recognized disease problem throughout the world (Griner, 1974). Since Scott (1927) first reported Plasmodium sp. in a King penguin (Aptenodytes patagonicus), reports of malaria in penguins have implicated only two parasite species, Plasmodium relictum and Plasmodium elongatum. Plasmodium elongatum has been reported in Humboldt penguins (Spheniscus humboldti) (Huff and Shiroishi, 1962) and African black-footed penguins (Spheniscus demersus) (Fleischman and Squire, 1968; Fleischman et al., 1968; Herman et al., 1968; Stoskopf and Beier, 1979). The more widely distributed $P$. relictum, in addition to the above species, has been reported in several other captive penguin species from North America (Griner and Sheridan, 1967; Laird and van Riper, 1981) as well as Europe (Rodhain, 1939; Grunberg and Kutzer, 1963).

Plasmodium relictum has been de- 
scribed in four species of free-living penguins by Fantham and Porter (1944) and in wild yellow-crowned penguins $(E u$ dyptes antipodes) from New Zealand (Laird, 1950). These two reports represent the only descriptions of avian malaria in wild penguins to date; however, there are very few hematological surveys in freeliving penguins. This paper presents the first record of avian malaria in captive Magellanic penguins (Spheniscus magellanicus), reviews clinical and pathological features of this disease, and describes a unique epidemiologic situation characterized by three distinct waves of mortality after arrival from quarantine in early spring.

\section{CASE HISTORY}

The Blank Park Zoo (7901 SW 9th Street, Des Moines, Iowa 50315, USA) received 46 Magellanic penguins on 26 April 1986. These birds were part of a larger group collected in midFebruary 1986 from the subantarctic island of Noir $\left(54^{\circ} 30^{\prime} \mathrm{S}, 73^{\circ} 00^{\prime} \mathrm{W}\right)$, a small rocky island off the southern coast of Chile. After collection ended in late February, all birds were shipped to the mainland of Chile and an undetermined number sent to Japan. The remainder of the group was held in outdoor pens on the coastal beach until 15 March 1986 and then flown via Santiago, Chile to Toronto, Ontario (Canada M5H 2N2). They arrived 18 March 1986. Quarantine began the next day in Detroit, Michigan (USA) after flight from Toronto. The total quarantine period lasted 38 days at a USDA-regulated privately owned import station (International Animal Exchange, Inc., 1489 East Nine Mile Road, Ferndale, Michigan 48220, USA). The only animals present in the quarantine facility during this time were penguins from this catch group. For aspergillosis prophylaxis during quarantine, oral ketaconazole (Nizoral, Janssen Pharmaceutica, Inc., Piscataway, New Jersey 08854, USA) was initiated in all birds at a dose of $50 \mathrm{mg} / \mathrm{bird} /$ day. When quarantine ended on 26 April 1986, birds were dispersed to three institutions; six to a facility in Maine (details unavailable), 18 to the Potter Park Zoo (1301 South Pennsylvania Avenue, Lansing, Michigan 48910, USA), and 46 to the Blank Park Zoo in Des Moines, Iowa. In Des Moines, the first malaria-associated death occurred $48 \mathrm{hr}$ after arrival and was diagnosed by histologic tissue evaluation (massive endothelial schizogony). Birds shipped to Michigan also experienced mortality, but cases of malaria were not confirmed by postmortem examination (gross and histologic evaluation) of the Michigan birds. Personal communications revealed that all of the Maine birds died without being subjected to necropsy, however penguins sent directly to Japan from Chile suffered no casualities (T. Hunt, pers. comm.).

\section{MATERIALS AND METHODS}

Beginning 26 April 1986, 46 wild-caught Magellanic penguins were housed as a temporary expediency in the outdoor penguin exhibit at the Blank Park Zoo. This exhibit was originally designed to house 20 birds. All birds were weighed upon arrival and maintained on a variety of fish (capelin, herring, anchovy, and smelt) as well as squid. Most birds required assisted feeding for a prolonged time after arrival. Daily dietary supplements per bird included multi-vitamins (Sea Tab, Pacific Research Laboratories, Inc., El Cajon, California 92022, USA; one quarter tablet), vitamin Bl (Goldline Laboratories, Ft. Lauderdale, Florida 33309, USA; $100 \mathrm{mg}$ ), salt (Eli Lilly and Co., Indianapolis, Indiana 46285, USA; $1 \mathrm{~g}$ ), and vitamin E (Jameson Nutritional Corp., San Mateo, California 94401, USA; 100 IU). Ferrous gluconate (Fergon, Winthrop Products, Division of Sterling Drugs, Inc., New York, New York 10016, USA; $320 \mathrm{mg} / \mathrm{bird}$ ) was supplemented twice weekly. After the initial malarial mortality, routine hematological screens (complete blood count, packed cell volume, differential, and total protein) and direct blood smear examinations (HEMA-TEK Modified Wright's stain, Ames Division, Miles Laboratories, Inc., Elkhart, Indiana 46515 , USA) were performed periodically on healthy birds as well as those with evidence of clinical disease. Using the blood smear from the only bird with detectable erythroparasitemia, intraerythrocytic parasite intensity was determined by counting 1,000 cells under oil immersion and calculating the percent of erythrocytes infected with both meronts and gamonts. Other antemortem diagnostic tests included sodium nitrate fecal flotation (Fecasol, Evsco Pharmaceuticals, Immunogenetics, Inc., Buena, New Jersey 08310, USA), radiography, and cloacal swab bacteriologic culture for birds with clinical evidence of diarrhea. All bacteriology was performed at the Iowa Methodist Medical Center (1200 Pleasant St., Des Moines, Iowa 50309, USA). For aerobic culture, samples were plated on blood and MacConkey agar and incubated at $35 \mathrm{C}$. Antibiotic sensitivities were determined with a Microscan System (Baxter Microscan, West Sacramento, California 95691, USA). Anaerobic cultures were identified with an An-IDENT System (API Analytab Products, 
Division of Sherwood Medical, Plainview, New York 11803, USA).

All 38 penguins that died between 28 April 1986 and 8 December 1986 were necropsied and gross lesions recorded. Impression smears from liver and spleen were made from several suspect individuals and stained with Diff-Quick (American Scientific Products, McGraw Park, Illinois 60085, USA) for microscopic examination. Representative tissues (liver, lung, kidney, spleen, heart, brain, intestine and gonads) from 20 individuals were fixed in $10 \%$ neutral buffered formalin. After routine paraffin processing, tissues were sectioned at $5 \mu \mathrm{m}$ and stained with hematoxylin and eosin (H\&E) for light microscopic examination. Special stains for bacteria (gram, acid-fast) and fungi (periodic acid-Schiff, Grocott's methenamine silver) were done where necessary (Sheehan and Hrapchak, 1980).

For examination by transmission electron microscopy, formalin-fixed tissues (heart and lung) from two infected birds were immersed in $3 \%$ glutaraldehyde in a $0.1 \mathrm{M}$ sodium phosphate buffer at $\mathrm{pH} 7.3$, and postfixed in $1 \%$ osmium tetroxide in the same buffer. After acetone dehydration, tissues were infiltrated and embedded in epoxy resin (EMbed 812, Electron Microscope Sciences, Box 251, Fort Washington, Pennsylvania 19034, USA). After sectioning, tissues were stained with $2 \%$ methanolic uranyl acetate (Stempak and Ward, 1964) and Reynold's lead citrate (Reynolds, 1963) and examined with a Hitachi HS-9 transmission electron microscope (Hitachi Instruments, Santa Clara, California 95050, USA).

For epidemiologic interpretation and assessment of potential mosquito populations, climatological data for Detroit, Michigan (March and April 1986) was obtained from the National Oceanic and Atmospheric Administration (U.S. Department of Commerce, National Climatic Data Center, Asheville, North Carolina 28801, USA). Similar data for Des Moines, Iowa was obtained from a local television weather station (WOI-TV, WOI Building, Ames, Iowa 50011, USA).

Representative tissue and blood smear specimens have been deposited in the U.S. National Parasite Collection (Beltsville, Maryland 20705, USA) as collection number 79928 .

\section{RESULTS}

\section{Clinical findings and treatment}

On arrival from quarantine, the average weight of all penguins was $3.29 \mathrm{~kg}$ (range $2.65-4.90 \mathrm{~kg}$ ). Nine individuals showed signs varying from inactivity and weakness to dyspnea, pale mucous membranes, and regurgitation of force-fed fish. The dose of oral ketaconazole was reduced from the level initiated in quarantine $(50 \mathrm{mg} / \mathrm{bird} /$ day to $12 \mathrm{mg} / \mathrm{bird} /$ day) because of concern about ketaconazole toxicity. After postmortem diagnosis of malaria in the first bird, all birds were placed on primaquine phosphate (Aralen, Winthrop-Breon Laboratories, Division of Sterling Drugs, New York, New York 10016, USA; 3 mg/bird/ day) and chloroquine phosphate (Rugby Laboratories, Inc., Rockville Centre, New York 11570, USA; $30 \mathrm{mg} / \mathrm{bird} /$ day). After 4 mo of this therapeutic regimen (1 May to 1 September 1986), the dose of primaquine was increased to $7.5 \mathrm{mg} / \mathrm{bird} / \mathrm{day}$ and chloroquine therapy stopped in an attempt to control the recurring malaria. Since these drugs differ in the stage of malaria they affect (primaquine against exoerythrocytic stages; chloroquine against erythrocytic stages), this change should have improved treatment of this primarily exoerythrocytic epizootic (Webster, 1985).

Erythrocyte counts, packed cell volumes, and total protein values were generally unremarkable. Leukocyte counts revealed a leukocytosis and absolute lymphocytosis in several individuals. Parasitized erythrocytes were detected in only one individual and totaled $13 \%$ infected cells (11\% meronts; $2 \%$ gamonts).

Other clinical findings included thoracic radiography and respiratory rales compatible with aspergillosis, fecal ova counts indicative of helminthiasis, and bacterial enteritis attributable to gram negative bacteria. Enteritis was diagnosed on the basis of monotypic cloacal cultures and the presence of diarrhea. All penguins with dyspnea and radiographic evidence of aspergillosis in air sacs were treated for aspergillosis. After initial diagnosis of aspergillosis at postmortem in several birds, antifungal therapy was changed from prophylactic ketaconazole to intravenous amphotericin B (Fungizone, E. R. Squibb and Sons, Inc., Princeton, New Jersey 08540, USA; $0.25 \mathrm{mg} / \mathrm{kg} /$ day) for 7 to 10 days. Although certain individuals made a clin- 


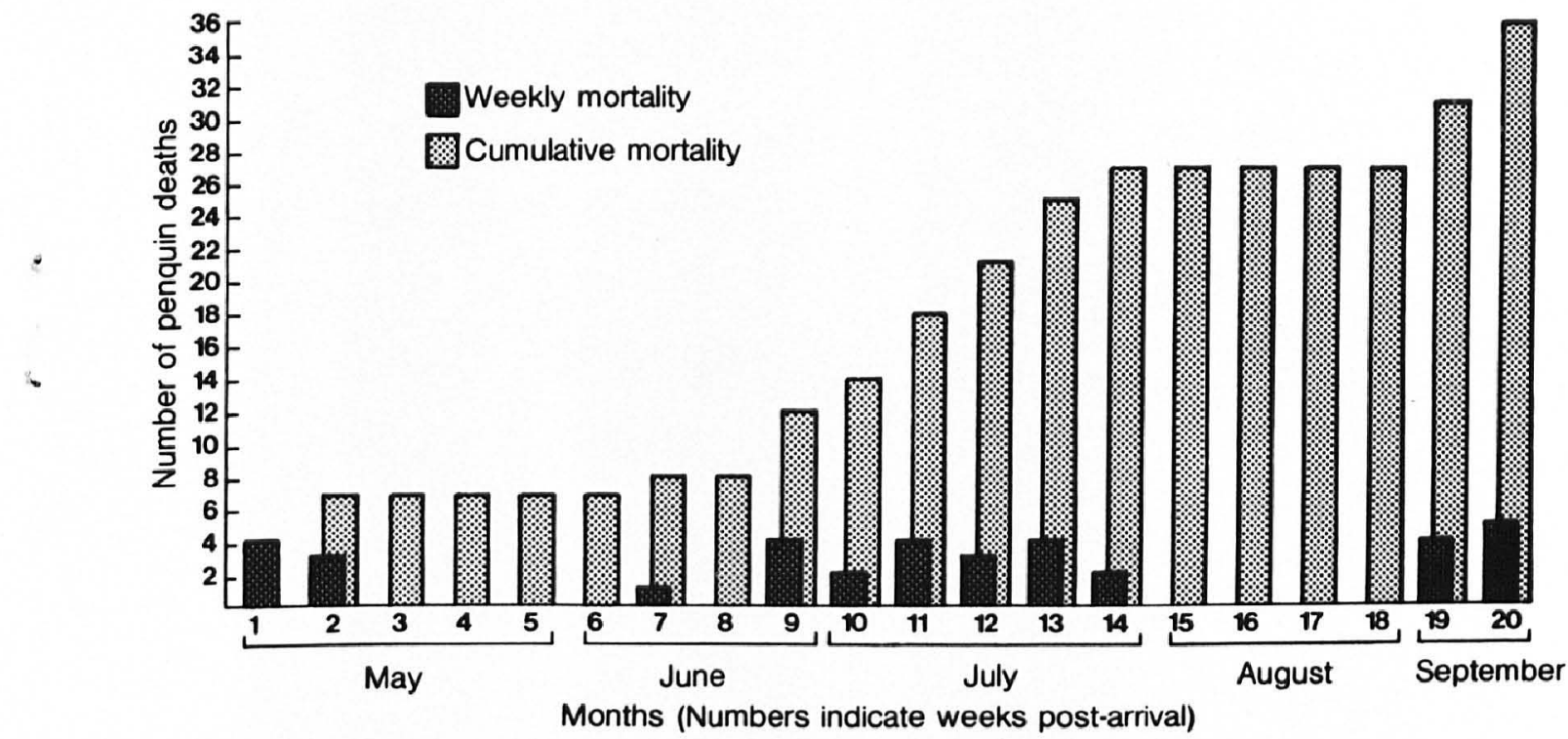

Figure 1. Temporal distribution of mortality during 1986 for Magellanic penguins infected with Plasmodium relictum. Note three distinct waves of mortality separated by a hiatus of 1 month. Two additional birds died sporadically during late fall for a total of 38 birds lost.

ical response based on amelioration of respiratory signs and air sac clearing radiographically, the continued persistence of the infection required modification of amphotericin B administration from intravenous to endotracheal delivery $(1 \mathrm{mg} / \mathrm{kg}$ twice daily increased to $3 \mathrm{mg} / \mathrm{kg}$ for 1 to $3 \mathrm{wk}$ ). In addition, several birds diagnosed with aspergillosis later in the summer were treated with oral flucytosine (Ancobon, Roche Laboratories, Division of HoffmanLa Roche, Inc., Nutley, New Jersey 07110, USA; $250 \mathrm{mg} /$ bird twice daily). Retrospective evaluation of clinical, radiographic, and necropsy details in this series of cases suggests that endotracheal amphotericin B was most efficacious.

Fecal flotations were repeatedly negative for helminth eggs, however adult ascarids (Contracaecum sp.) were found from regurgitating birds and cestode segments (Tetrabothrius sp.) were evident in feces. All penguins were treated with ivermectin (Ivomec, MSDAGVET, Division of Merck and Co., Inc., Rahway, New Jersey 07065, USA; $200 \mu \mathrm{g} / \mathrm{kg}$ ).

Cloacal cultures from birds with clinical evidence of diarrhea yielded growths of
Escherichia coli, Clostridium perfringens, Proteus vulgaris, Plesiomonas shigelloides, Bacteriodes melaninogeniais, and Edwardsiella sp. Individual antibiotic sensitivities determined by the Microscan System dictated appropriate antimicrobial selection for treatment. Amelioration of diarrhea was variable between individuals.

Penguin mortality occurred in three distinct waves (Fig. 1). Wave 1 lasted 13 days and seven birds died. The second wave persisted 50 days with the loss of 20 birds. Nine additional birds died during 13 days of the third wave. Each wave was separated by a distinct hiatus of approximately 1 mo. Two additional deaths occurred sporadically in late fall, bringing the total number of deaths in 1986 to 38 .

\section{Gross findings}

All 38 of the penguins that died were necropsied. Gross lesions typical of avian malaria, including splenomegaly, hepatomegaly and severe pulmonary edema were evident in 22 birds (58\%). Three of these birds also had cardiomegaly with dark green pericardial effusion. In those birds so examined, impression smears of liver 


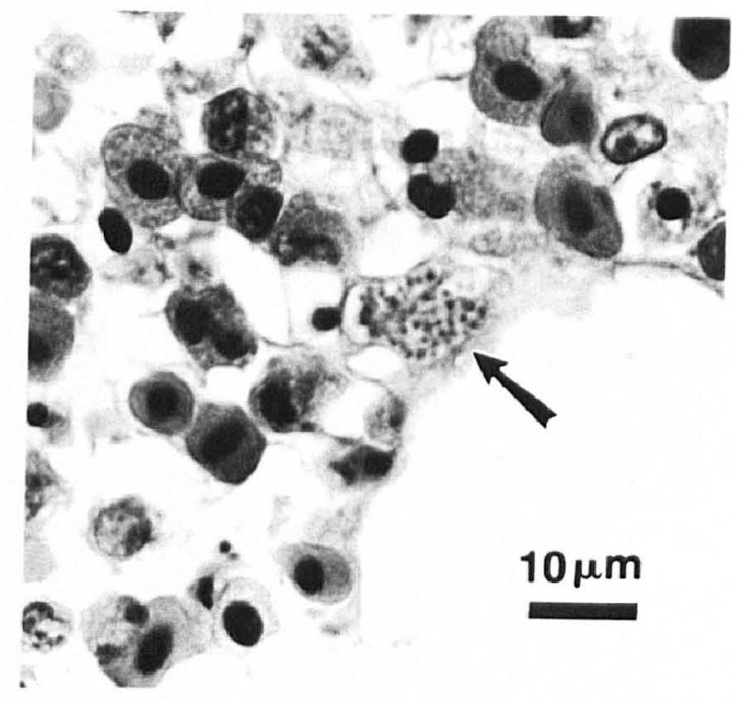

FIGURE 2. Plasmodium relictum schizont in pulmonary capillary endothelium (arrow). H\&E.

and spleen failed to reveal protozoa schizonts. Granulomatous air sacculitis from aspergillosis was evident in 23 birds $(61 \%$; 12 cases alone and 11 cases concurrent with malaria). Helminths, evident in 10 birds (26\%), were identified from the stomach as ascarids (Contracaecum sp.) and from the intestine as cestodes (Tetrabothrius sp.). Other findings included occasional abdominal serosanguineous fluid and a single case of coxo-femoral osteomyelitis secondary to aspergillosis.

\section{Microscopic findings}

Tissues from 20 birds were examined histologically. Of the 22 previously mentioned birds with gross lesions typical of malaria, 13 were examined histologically and all had extensive endothelial schizogony in multiple parenchymal organs. Tissues most consistently affected, primarily spleen, lung and liver, were characterized by massive numbers of protozoal schizonts in capillary endothelium (Fig. 2) and macrophages. Schizonts frequently occluded vessels and were particularly common in splenic and pulmonary macrophages. Many pulmonary parabronchi were densely infiltrated by sheets of macrophages. Occasionally schizonts were evident in

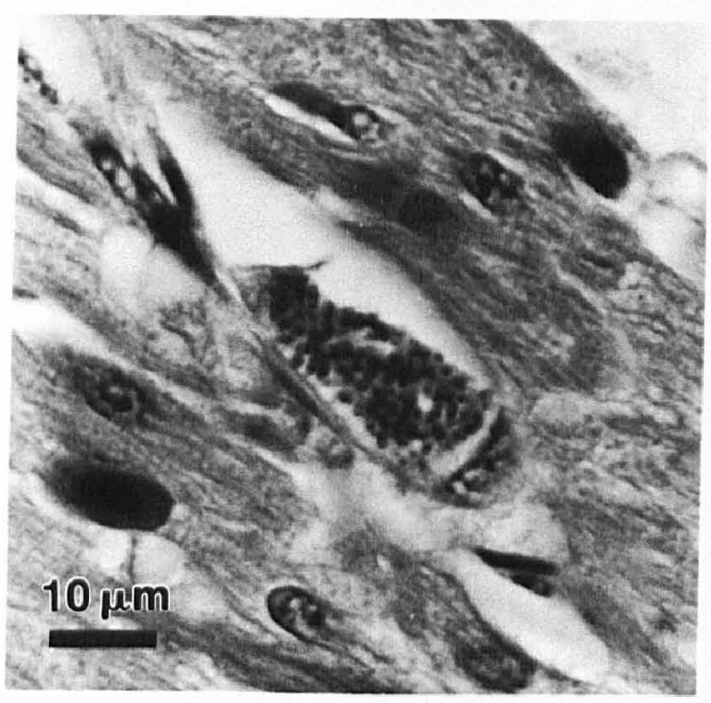

Figure 3. Large Plasmodium relictum schizont in cardiac endothelium. Note tendency to occlude vessel. $\mathrm{H} \& \mathrm{E}$.

renal, brain and cardiac endothelium. Penguins with gross cardiomegaly and pericarditis had fulminating myodegeneration from massive schizogony (Fig. 3). The inflammatory response varied considerably but frequently included many lymphocytes and plasma cells with fewer numbers of heterophils and macrophages. Other findings commonly encountered were chronic lymphoplasmacytic enteritis in 12 of 20 birds examined histologically (60\%), splenic and pulmonic hemosiderosis, and caseonecrotic granulomatous air sacculitis with numerous fungal hyphae typical of Aspergillus fumigatus.

\section{Parasite identification}

Exoerythrocytic schizonts were frequently detected in spleen, lung and liver from 13 of 20 penguins examined histologically. Schizonts were found less frequently in heart, brain, kidney and intestine. These were small, measuring 16 to $28 \mu \mathrm{m}$ by 11 to $16 \mu \mathrm{m}$. Mature segmenters with two distinct sizes of merozoites were seen. The larger merozoites (macromerozoites) contained nuclei measuring $1.0 \mu \mathrm{m}$ whereas the smaller merozoites (micromerozoites) contained nuclei about half as 


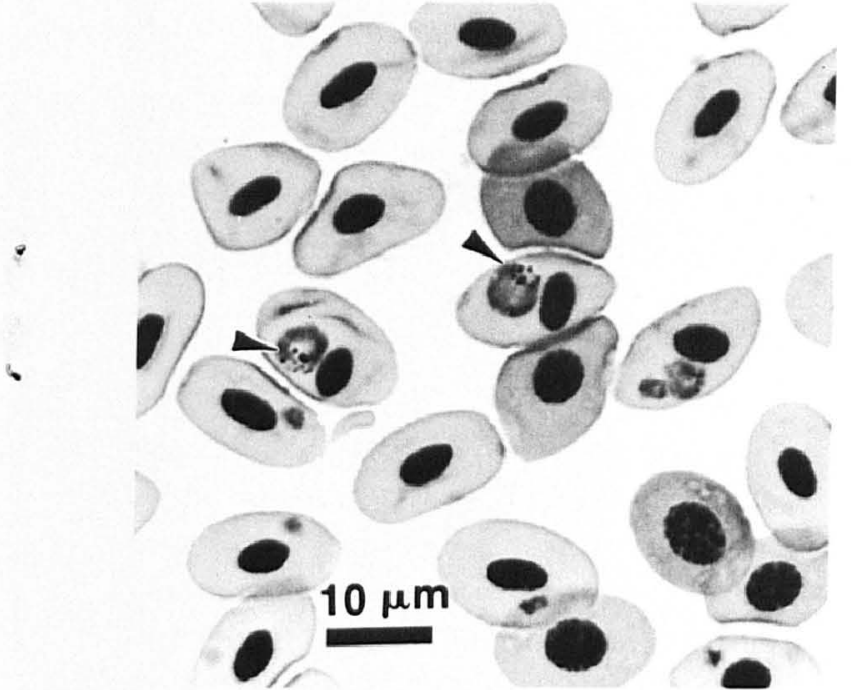

Figure 4. Intraerythrocytic Plasmodium relictum gametocytes. Displacement and rotation of the erythrocyte nucleus is characteristic. Note fine, punctate pigment granules (arrows). Wright's stain.

large. Ultrastructurally, merozoites within schizonts from heart and lung contained a distinct apical complex with tear-shaped rhoptries. Although transmission electron microscopic details from these formalized tissues were less than ideal, their apicomplexan identity was firmly established and matched closely the evidence presented at the light microscopic level.

Erythrocytic stages were seen only on one blood smear from the last penguin that died (8 December 1986). These corresponded to the morphology of Plasmodium relictum in having round gametocytes that displaced and turned the infected erythrocyte nucleus (Fig. 4). The schizonts were round and averaged 10.1 (range $=8$ to 12) merozoites/segmenter (Fig. 5).

\section{Climatological data}

During the quarantine period in spring of 1986, Detroit, Michigan, experienced almost nightly killing frosts through 28 March, despite slightly warmer than average temperatures. Additionally, subfreezing temperatures occurred on 12, 13 and 21 April. This was combined with

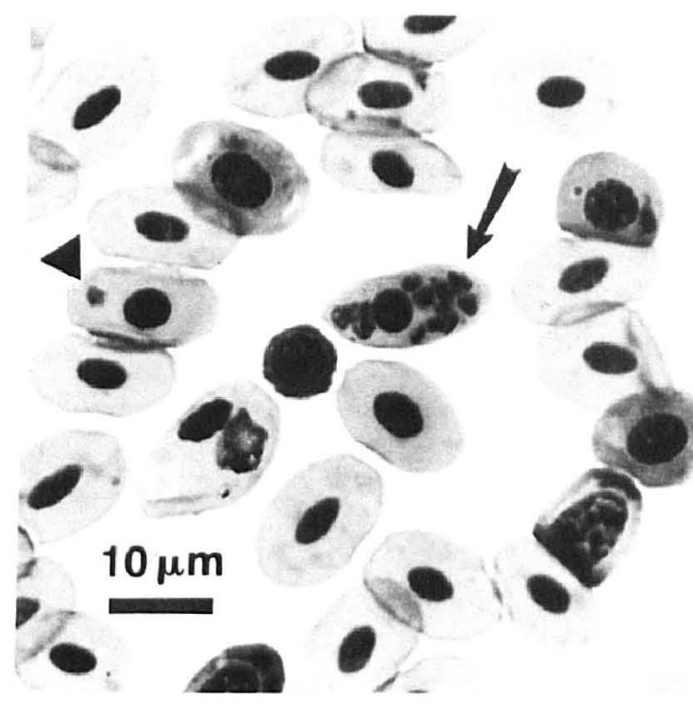

FIgURE 5. Intraerythrocytic merozoites of Plasmodium relictum (arrow). Segmenters typically have 8 to 12 merozoites per meront. Note young trophozoite (arrowhead). Wright's stain.

March precipitation totals $10 \%$ below mean and April precipitation 12\% below mean.

In contrast to the cold and dry weather in Detroit, the 1986 spring weather in Des Moines, Iowa, was warm and wet. Early April temperatures were consistently $\geq 8$ degrees above average. Temperatures fell below freezing on only two days in April. In addition, precipitation levels were the sixth wettest on record for Des Moines.

\section{DISCUSSION}

Clinical and pathological details of avian malaria in the Magellanic penguins of this report agree with similar outbreaks previously described (Grunberg and Kutzer, 1963; Griner and Sheridan, 1967; Fleischman et al., 1968). In each outbreak, several captive penguins displayed typical clinical signs, had similar gross and histologic lesions, and experienced significant mortality. Definitive studies regarding specific pathogenic disease mechanisms in malaria-infected penguins are lacking. However, the massive endothelial exoerythrocytic schizogony so characteristic of this disease in penguins must certainly contribute heavily to the pathogenesis. The 
normal vascular endothelium participates in a multiplicity of homeostatic events (Simionescu and Simionescu, 1986). Disturbances in its integrity can result in many well-recognized pathogenic processes (Wall and Harker, 1980). It seems likely that endothelial damage, along with vascular occlusion from the physical presence of endothelial schizonts, may play a prominent role in the parenchymal organ dysfunction and failure that results in the death of the affected host. In addition, the pulmonary edema and macrophage infiltrate likely leads to respiratory failure.

Why only one penguin had a detectable parasitemia during this epizootic is not understood. The erythrocyte infection rate in this individual (13\%) was tremendous relative to other reports of Plasmodium sp. in penguins (Stoskopf and Beier, 1979), which indicate intensities of $<0.01 \%$. Perhaps this bird experienced recrudescence of infection, suffered individually from massive exposure or was immunocompromised. Since parasitemias in Plasmodium sp.-infected penguins are difficult to detect by routine antemortem techniques (Stoskopf and Beier, 1979), isodiagnosis (subinoculation) may be used (Herman et al., 1966; Stoskopf and Beier, 1979). Although this procedure could have fulfilled Koch's postulates, economic constraints prohibited the utilization of this technique in our case. However, its usefulness should not be ignored in similar future situations.

Characteristic hematological changes during Plasmodium sp. infection have been described in African black-footed penguins (Stoskopf and Beier, 1979). Several of our infected Magellanic penguins had similar hematological alterations (increased total leukocytes with absolute increase in lymphocytes), but no definitive correlation could be made between malarial infection and hematological changes. This may have been due to the high prevalence of concurrent disease in this particular group of birds.

The persistence of malaria in the face of standard antimalarial therapy in our case is unexplained. Previous experience with similar therapy for treatment of Plasmodium relictum in penguins is limited, but has apparently been effective (Griner and Sheridan, 1967). In treatment of human malaria, acquired resistance usually occurs subsequent to previous or continuous drug exposure, but natural refractoriness or insensitivity is also documented (Webster, 1985). Since antimalarial drugs were given to our penguins for up to $5 \mathrm{mo}$, some degree of selective chemotherapeutic resistance may have complicated any pre-existing natural insensitivity. In addition, drug levels may not have been optimum since specific pharmacokinetics of antimalarial drugs have not been determined in penguins and dosages have merely been extrapolated from other species.

Previous reports of malaria in captive penguins have described single summer or fall outbreaks (Griner and Sheridan, 1967; Fleischman et al., 1968; Herman et al., 1968; Beier and Stoskopf, 1980). In contrast, our case documents early spring occurrence with multiple waves of mortality. In addition, our recently captured penguins were still under considerable stress from capture, transport and quarantine, unlike the captive birds housed in zoos in previous cases. To explain the dramatic appearance of malaria in penguins dying shortly after arrival in Des Moines, four potential points of infection must be examined: native habitat, Chilean coastal beach, quarantine in Detroit, Michigan, and Des Moines, Iowa.

The failure to document malaria, either postcapture, posttransport or postquarantine, in birds of the same original group but from other facilities argues strongly against the point of infection being native habitat, Chilean coastal beach, or quarantine. The recrudescence of a precapture, subclinical infection due to immunosuppression is unlikely, but cannot be ruled out completely since infection with Plasmodium relictum has been reported from wild African black-footed penguins (Fanthan and Porter, 1944), a species closely 
related to Magellanic penguins. Birds shipped directly to Japan from Chile experienced no mortality. Infection during quarantine should have produced mortality in the birds sent to the zoo in Lansing, Michigan, but none occurred.

Climatic conditions during quarantine would have made the potential for any appreciable mosquito populations relatively small, thus minimizing the chances of exposure to malaria. Data cited from the NOAA national weather office in Detroit, Michigan supports this. However, no scientific studies were made during quarantine to document the existence of mosquitoes or to determine the potential for possible exposure.

With consideration of the above data, exposure to malaria likely occurred after arrival in Des Moines. Local weather conditions were very conducive to early mosquito populations. Temperatures were well above average during April and precipitation quite heavy. Although no specific mosquito census or population studies were done in Des Moines postarrival, known mosquito vector species for $P$. relictum exist in central Iowa and may have been important in our epizootic. Both Culex pipiens and Culex tarsalis are documented P. relictum vectors (Rodhain, 1939; Coulston and Huff, 1947; Rosen and Reeves, 1954) and are common in central Iowa (Pinger and Rowley, 1972). Although specific mosquito involvement is speculative, the necessary climatic and vector conditions existed in Des Moines for exposure to malaria.

The major argument against infection in Des Moines is the rapid appearance of the disease. This would have to be considered a peracute form of avian malaria. Plasmodium relictum has two exoerythrocytic schizont generations prior to erythrocytic invasion (Huff, 1951), the first of which requires 36 to $48 \mathrm{hr}$ for completion, at least in passerines (Garnham, 1966). In experimentally inoculated canaries and pigeons, exoerythrocytic schizonts have been detected as early as $18 \mathrm{hr}$ postinoculation and contain 20 to 25 merozoites by 36 to $50 \mathrm{hr}$ (Coulston and Huff, 1947). Based on this, it is certainly possible that in our penguins enough pre-erythrocytic parasite development could have occurred within 2 days to produce mortality. In this scenario, complete pre-erythrocytic development and subsequent erythrocyte invasion is unnecessary for pathogenicity as massive intraendothelial schizogony would account for mortality. Since Plasmodium relictum life cycle data has been generated from experimental passerine inoculation where development time varies with parasite strain and host species (Coulston and Huff, 1947; Huff, 1951; Garnham, 1966), extrapolation of this data to penguins may not be valid. The rapid onset and unusual behavior of $P$. relictum in these Magellanic penguins could easily be attributed to temporal variability in life cycle stage development.

In light of the evidence presented here, serious implications exist for testing, therapy and prophylaxis of malaria in captive penguins. The extremely rapid progression of disease described above indicates that many birds could become infected and die during the time between routine blood samplings. Additionally, unseasonable weather effects on mosquito populations should alert managers relying on standard prophylactic regimens for prevention of malaria-associated fatalities. The early wave of mortalities in this group of penguins occurred long before most programs would have begun antimalarial treatment.

Several other factors need to be considered in total assessment of this outbreak. Concurrent diseases present in these penguins (aspergillosis, bacterial enteritis, and helminth parasitism) are well-recognized problems reported in captive penguins. Aspergillosis is a common respiratory disease, has contributed significantly to mortality in several cases, and is important in recently imported, unacclimated penguins (Khan et al., 1977; Gailey-Phipps, 1978; Schmidt, 1978). Information regarding the role of bacteria as enteric patho- 
gens in penguins is limited. Documented problems concerning pathogenic E. coli (Stoskopf and Beall, 1980) and Edwardsiella tarda (Cook and Tappe, 1985) have been reported. In addition, bacteria from dietary fish must be considered when interpreting cloacal culture results from piscivorous birds. The specific contribution helminth parasitism made to overall mortality is unknown, although it probably was not significant.

Finally, the role of stress in this epizootic of avian malaria cannot be ignored. Although some of the birds were weak upon arrival, presenting weights were well within normal limits for Magellanic penguins recorded in the wild (Boswall and MacIver, 1975). This suggests that these birds were at least eating and not severely maladapted during quarantine. Since physical and psychological stress can produce immunosuppression by endogenous corticosteroid release (Feldman, 1983), it is likely that capture, transport, quarantine and concurrent disease all contributed to stress and subsequent immunosuppression in this group of birds. Overcrowding upon arrival may have been an additional stressor. All of the above factors must be considered when attempting to explain the apparent inability of this group of penguins to cope with their malarial parasitism. Penguins are hardy creatures in their native habitat and do quite well in captivity under many circumstances.

\section{ACKNOWLEDGMENTS}

The authors wish to thank Jay Tappe, National Animal Disease Center, Ames, Iowa, for initial diagnosis and consultation. Thomas Bell and Jim Sikarski of Michigan State University's College of Veterinary Medicine kindly provided clinical and pathological data from penguins that went to the Potter Park Zoo in Lansing, Michigan. John Greve of Iowa State University identified the helminth parasites. We also thank Martin Young and Don Forrester of the University of Florida for consultation, Wayne Rowley of Iowa State University for entomological data, and Don Novak, WOI television, Ames, Iowa for climatological information. Larry Arp and Craig Harms reviewed the manuscript.
Jane Fagerland and Marianne Brack assisted with electron microscopy. Myrna Booth and Frida Eklund of the Blank Park Zoo helped considerably with animal care. Support for this project was provided by the Blank Park Zoo, Des Moines, Iowa, and the Department of Veterinary $\mathrm{Pa}$ thology, College of Veterinary Medicine, Ames, Iowa.

\section{LITERATURE CITED}

Beier, J. C., And M. K. Stoskopf. 1980. The epidemiology of avian malaria in black-footed penguins (Spheniscus demersus). Journal of Zoo Animal Medicine 11: 99-105.

Boswall, J, AND D. MaCIver. 1975. The Magellanic penguin Spheniscus magellanicus. In The biology of penguins, B. Stonehouse (ed.). University Park Press, Baltimore, Maryland, pp. 271305.

CoOK, R. A., And J. P. TAppe. 1985. Chronic enteritis associated with Edwardsiella tarda infection in Rockhopper penguins. Journal of the American Veterinary Medical Association 187: 1219-1220.

Coulston, F., and C. G. huff. 1947. The morphology of cryptozoites and metacryptozoites of Plasmodium relictum and the relationship of these stages to parasitemia in canaries and pigeons. Journal of Infectious Diseases 80: 209-217.

Fantham, H. B., AND A. Porter. 1944. On a Plasmodium (Plasmodium relictum var. spheniscidae, n. var.), observed in four species of penguins. Proceedings of the Zoological Society of London 114: 279-292.

Feldman, E. C. 1983. The adrenal cortex. In Textbook of veterinary internal medicine, 2 nd ed., S. J. Ettinger (ed.). W. B. Saunders Co., Philadelphia, Pennsylvania, pp. 1650-1696.

Fleischman, R. W., and R. A. SQuire. 1968. Pathologic confirmation of malaria (Plasmodium elongatum) in African penguins (Spheniscus demersus). Bulletin of the Wildlife Disease Association 4: 133-135.

,,-- W. J. L. SLADEN, AND E. C. MELby, JR. 1968. Malaria (Plasmodium elongatum) in captive African penguins (Spheniscus demersus). Journal of the American Veterinary Medical Association 153: 928-935.

GAILEY-PHIPPS, J. 1978. A world survey of penguins in captivity. International Zoo Yearbook 18: 713.

Garnham, P. C. C. 1966. Malaria parasites and other haemosporidia. Blackwell Scientific Publications, Oxford, England, pp. 522-550.

GRINER, L. A. 1974. Avian malaria in penguins. Advances in Veterinary Science and Comparative Medicine 18: 251-271.

, AND B. W. Sheridan. 1967. Malaria (Plasmodium relictum) in penguins at the San Diego 
Zoo. American Journal of Veterinary Clinical Pathology 1: 7-17.

GrunberG, W., AND E. KuTzer. 1963. Infektionen mit Plasmodium praecox bei Humboldt (Spheniscus humboldti) und Brillenpinguinen (Spheniscus demersus). Zentralblatt für Bakteriologie, Parasitenkunde, Infektionskrankheiten und $\mathrm{Hy}$ giene. Erste Abteilung Originale. 189: 511-520.

Herman, C. M., J. O. Knisley, and E. L. Snyder. 1966. Subinoculation as a technique in the diagnosis of avian Plasmodium. Avian Diseases 10: 541-547.

-, R. M. Kocan, E. L. SNyder, and J. O. KNISLEY, JR. 1968. Plasmodium elongatum from a penguin. Bulletin of the Wildlife Disease Association 4:132.

HUFF, C. G. 1951. Observations on the pre-erythrocytic stages of Plasmodium relictum, Plasmodium cathemerium, and Plasmodium gallinaceum in various birds. Journal of Infectious Disease 88: 17-26.

- AND T. SHIROISHI. 1962. Natural infection of Humboldt's penguin with Plasmodium elongatum. The Journal of Parasitology 48: 495.

KHAN, Z. U., M. PAL, D. K. PALIWAL, AND V. N. Damodaran. 1977. Aspergillosis in imported penguins. Sabouraudia 15: 43-45.

LAIRD, M. 1950. Some blood parasites of New Zealand birds. Zoology Publications from Victoria University College 5: 2-15.

- AND C. VAN RIPER III. 1981. Questionable reports of Plasmodium from birds in Hawaii, with the recognition of $P$. relictum ssp. capistranoae (Russell, 1932) as the avian malaria parasite there. In Parasitological topics, E. V. Canning (ed.). Society of Protozoologists, 1981 Special Publication \#1, Allen Press, Inc., Lawrence, Kansas, pp. 159-165.

Pinger, R. R., JR., AND W. A. Rowley, 1972. Occurrence and seasonal distribution of Iowa mosquitoes. Mosquito News 32: 234-241.

REYNOLDS, E. S. 1963. The use of lead citrate at high $\mathrm{pH}$ as an electron-opaque stain in electron microscopy. Journal of Cell Biology 17: 208-212.

RodhaIN, J. 1939. L'infection a Plasmodium relictum chez les pingouins. Annales de Parasitologie Humaine et Comparée 17: 139-157.
Rosen, L., and W. C. Reeves. 1954. Studies on avian malaria in vectors and hosts of encephalitis in Kern County, California. III. The comparative vector ability of some of the local culicine mosquitoes. American Journal of Tropical Medicine and Hygiene 3: 704-708.

SCHMIDT, C. R. 1978. Humboldt's penguins (Spheniscus humboldti) at the Zurich Zoo. International Zoo Yearbook 18: 47-52.

SCOTT, H. H. 1927. Report on the deaths occurring in the society's gardens during the year 1926. Proceedings of the Zoological Society of London 1927: 173-198.

Sheehan, D. C., and B. B. Hrapchak. 1980. Theory and practice of histotechnology, 2 nd ed. The C. V. Mosby Company, St. Louis, Missouri, 481 pp.

Simionescu, M., And N. Simionescu. 1986. Functions of the endothelial cell surface. Annual Review of Physiology 48: 279-293.

StempaK, J. G., AND R. T. Ward. 1964. An improved staining method for electron microscopy. Journal of Cell Biology 22: 697-701.

Stoskopf, M. K., AND F. B. BEALL. 1980. The husbandry and medicine of captive penguins. Annual Proceedings of the American Association of Zoo Veterinarians, AAZV, Washington, D.C., pp. 81-96.

- AND J. BEIER. 1979. Avian malaria in African black-footed penguins. Journal of the American Veterinary Medical Association 175: 944-947.

Wall, R. T., AND L. A. Harker. 1980. The endothelium and thrombosis. Annual Review of Medicine 31: 361-371.

Weisster, L. T. 1985. Drugs used in the chemotherapy of protozoal infections. In Goodman and Gilman's the pharmacological basis of therapeutics, 7th ed., A. G. Gilman, L. S. Goodman, T. W. Thrall, and F. Murad (eds.). Macmillan Publishing Co., Inc., New York, New York, pp. 1029 1048.

Received for publication 25 November 1987. 